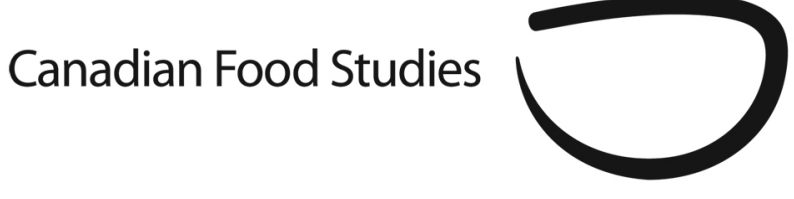

La Revue canadienne des études sur l'alimentation

Field Report

\title{
Insights from the Think\&EatGreen@School Project: How a community-based action research project contributed to healthy and sustainable school food systems in Vancouver
}

\author{
Alejandro Rojas ${ }^{a}$, Jennifer L. Black ${ }^{a^{*}}$, Elena Orrego ${ }^{a}, G^{\prime}$ en Chapman ${ }^{b}$, and Will \\ Valley $^{\mathrm{a}}$ \\ ${ }^{a}$ The University of British Columbia, Faculty of Land and Food Systems \\ ${ }^{b}$ University of Guelph, College of Social and Applied Human Sciences
}

\begin{abstract}
From 2010 to 2016, the Think\&EatGreen@School project worked to create healthy and sustainable school food systems in the Vancouver School Board. Using models of CommunityEngaged Scholarship and Community-Based Action Research, we implemented diverse programmatic and monitoring activities to provide students and teachers with hands-on food cycle education, in order to influence policy, and to encourage university students to engage actively with the food system. Our focus was on transformation of local school food systems as a context-specific means to address serious global issues related to food security, health and environmental sustainability. This paper provides a synthesis of the project including the context that led to its inception, its overarching goals, methodological framework and areas of impact. Key learnings from this project highlight the need for continued work to integrate research, teaching and action on global food security, environmental and public health challenges and to build connections to create healthy, sustainable school food systems.
\end{abstract}


Video: “Think and Eat Green at School: Embrace Change”, produced by Pedro Orrego and Peter Jestadt; edited by Peter Jestadt; music by Ronald Jenkees. https://www.youtube.com/watch?time_continue=2\&v=t2UA4iSKsYA

Keywords: food systems; community-engaged scholarship; community-based action research; school; Vancouver

\section{Introduction}

Think\&EatGreen@School (TEGS) was a 6 year project that brought university, public school, health, and community stakeholders together to work towards healthy, sustainable food systems in Vancouver schools (Think\&EatGreen@School, 2015). This paper's authors are food studies scholars affiliated with the Faculty of Land and Food Systems at the University of British Columbia (UBC) who were deeply involved in the project: three authors (Rojas, Valley, and Orrego) were involved from the pre-conception stage, and two (Black and Chapman) joined the project as co-investigators early on. With others involved in planning and conducting the project, we imagined the public-school system as a complex yet feasible setting for social learning experimentation to improve child health and environmental sustainability and to strengthen connections among university research, teaching and service roles and to align them with community needs and assets. Using models of Community-Engaged Scholarship and Community-Based Action Research, we implemented diverse programmatic and monitoring activities to provide students and teachers with hands-on food cycle education, in order to influence policy, and to encourage university students to engage actively with the food system. Our focus was on transformation of local school food systems as a context-specific means to address serious global issues related to food security, health and environmental sustainability. This paper provides a brief overview of TEGS, a discussion of the context from which it emerged, its goals, activities, areas of impact, and key lessons learned.

\section{The interlocking, critical challenges in contemporary food systems: Food security, environmental sustainability and population health and nutrition}

Think\&EatGreen@School was grounded in concerns about the vulnerabilities of our global food system and its local manifestations, particularly driven by the broad concept of food security and the intersections of food, sustainability, and health. We were struck by the question of "how we will feed the more than nine billion people projected to live on this planet by 2050?” (Foley, 2014; Fraser et al., 2016; Fraser \& Rimas, 2012; Godfray et al., 2010; Searchinger, 2013), and recognized that increased food production alone cannot guarantee a secure, equitable, and sustainable food system. Limitations of the current food system are clear from global estimates suggesting that approximately 795 million people were undernourished in 2014-16 (FAO, IFAD, \& WFP, 
2015). Even in affluent countries like Canada and the United States, over one in ten households report insufficient incomes to meet their food needs (Coleman-Jensen, Rabbitt, Gregory, \& Singh, 2016; Tarasuk, Mitchell, \& Dachner, 2016). These issues are further complicated by potential effects of climate change predicted to impact all aspects of food security including agricultural yields, water quality, and price stability (IPCC, 2014).

Children are frequently a focus for efforts to improve health and food security outcomes. International initiatives recognizing the importance of food for health and development are often aimed at reducing rates of low birth weights and childhood malnutrition (Scaling Up Nutrition, 2014). In affluent countries like Canada, nutrition-related conditions, previously considered mainly diseases of aging such as type-2 diabetes, are now emerging public health concerns among youth (MacPherson, de Groh, Loukine, Prud'homme, \& Dubois, 2016; Pelletier et al., 2012; Roberts, Shields, de Groh, Aziz, \& Gilbert, 2012). Children and youth have become a priority for public health nutrition initiatives in Canada including the federal Healthy Eating Strategy (Government of Canada, 2016; Health Canada, 2017; Tremblay, 2012), as eating habits and food preferences established in childhood appear to continue into adult years (Birch, 1999; Kelder, Perry, Klepp, \& Lytle, 1994; Mikkila, Rasanen, Raitakari, Pietinen, \& Viikari, 2005) and most Canadian children do not meet national dietary recommendations. National nutrition surveys show, for example, that few children are consuming the recommended number of servings of fruits and vegetables (Black \& Billette, 2013), and about a quarter of children's intake consists of "other foods" that are high in fat, sugar and/or sodium (Garriguet, 2007).

TEGS grew out of a recognition of the interconnections between health, nutrition and sustainability challenges. It also responded to a critique of reductionist approaches to understating complex systems by breaking them down into component parts and studying each separately. This perspective has created a situation in food studies, as in other fields, where academics and professionals become experts in individual components but fail to communicate across disciplines. For example, agronomists focus on increasing crop yields without adequately considering the implications for the economic and physical well-being of farmers, for the nutritional profile of foods produced, or for the health of the ecosystem. Nutritionists advocate diets that prevent disease but may originate from environmentally and socially unsustainable approaches to food production, processing, and transportation. Even when experts agree on interlinked impacts of activities within the food system, political contexts may prevent change, evidenced by the decision not to include sustainability goals in the 2015 USDA Dietary Guidelines (United States Department of Agriculture, 2015). Addressing food security, health, and sustainability concerns will require support and advocacy from an empowered citizenry and integrated efforts of scientists, practitioners and policymakers-and thus the development of Think\&EatGreen@School. 


\section{Responding to the challenges: Emergence of Think\&EatGreen@School}

To respond actively to food systems challenges, we focussed on the public education system, given its history of promoting social change by engaging the youngest members of society. Children spend a substantial portion of time in schools and most North American youth consume one or more meals at school on weekdays (Briefel, Crepinsek, Cabili, Wilson, \& Gleason, 2009; Briefel, Wilson, \& Gleason, 2009; Tugault-Lafleur, Black, \& Barr, 2017). The school context can influence students' understandings of and attitudes about the wider food system (Davis, Spaniol, \& Somerset, 2015; Hersch, Perdue, Ambroz, \& Boucher, 2014; Legault \& Pelletier, 2000; Welker, Lott, \& Story, 2016), including where food comes from and how food waste is managed. Schools have the potential to engage students with the entire food cycle and serve as key institutions where understandings of food, health and civic responsibility germinate (Feenstra, 2002; Rojas et al., 2011; Winson, 2010). Food topics may be integrated into curricula through diverse learning activities ranging from home economics, physical education, health and culinary arts courses directly focussed on life skills, to science, geography, social studies, or history where food opens doors to diverse lessons about biology, culture, and civic responsibility. School programs can influence the broader community too, as children share and promote food knowledge and practices they learn with their families. The school can also become a hub for interaction with surrounding communities to demonstrate and promote healthy, sustainable food practices.

Given the multiple levels on which engaging schools can influence food systems change, we began interacting with Vancouver public schools in the early 2000's. By 2010 the University of British Columbia had a working relationship with several elementary schools and developed curricular resources for food and garden learning for teachers (Mayer-Smith \& Peterat, 2010). Around the same time, the City of Vancouver had declared the intention to become "the greenest city in the world.” One of the ten goals in the 2020 Action Plan was that Vancouver would become a global leader in urban food systems, reached by dramatically increasing local food assets, including community gardens and urban farms (City of Vancouver, 2012).

A range of non-profit groups, including the Society Promoting Environmental Conservation (SPEC, 2017) and the Environmental Youth Alliance_(EYA, 2017), were creating programs to incorporate gardens into school curricula and engage youth with their food sources. Other groups like Growing Chefs and Project CHEF were engaging students in learning how to prepare local, healthy foods (Growing Chefs, 2017; Project Chef, 2017). Through public health organizations, school salad bars, and farm-to-school programs were initiated to provide healthy, sustainable food for students and to support local farmers (Mansfield, 2016). Nutritionists from the local health authority, Vancouver Coastal Health, were actively working with the Vancouver Board of Education to facilitate development of school gardens and healthy food programs. However, many groups were working independently, without sufficient knowledge of related initiatives. There was strong interest in forming a research collaboration to strengthen collective efforts beyond what was possible through individual action. 
Our decisions about what actions to take reflected our collective professional, theoretical, and methodological inclinations, and the institutional and geographic context. Key decisions included: the selection of public schools in Vancouver as the site for action; hands-on food system education as our focus; and Community Engaged Scholarship as our research paradigm, with university students as key catalysts of action and knowledge creation. We sought to learn by doing, and hypothesized that our broad community of learners would benefit through involvement.

Our hands-on whole food cycle approach was consistent with emerging conceptualizations of food literacy as an important area for development in the fields of health and education (Cullen, Hatch, Martin, Higgins, \& Sheppard, 2015; Sumner, 2013; Velardo, 2015). Like us, various health promotion professionals, nutrition educators, and community food activists have noted the critical need to improve the population's food-related knowledge, skills, and capacity to take action to address food-related health, environmental and economic issues. A number of definitions of food literacy have been now been proposed, typically incorporating knowledge about food production, food access, and nutrition, as well as practical skills in growing food, shopping, cooking, and composting.

The project also aligned with and informed the broader emergence of an alternative mission and approach for universities, which Trencher and colleagues call "co-creation for sustainability” (Trencher, Yarime, McCormick, Doll, \& Kraines, 2013). Traditionally, universities have focused on teaching and research, with entrepreneurship and contribution to economic development being added recently as a "third mission" (Etzkowitz, 2008). Co-creation for sustainability, however, positions universities in transformative roles addressing critical social and environmental needs. Transdisciplinary approaches that entail meaningful collaboration between academic, government, industry, and/or civil society stakeholders are central, as are participatory and action research, service learning, regional development, and living laboratories methodologies (Trencher et al., 2013).

\section{Research approach and objectives}

Community-Based Action Research (CBAR) was the central research approach used in TEGS, as it values the knowledge, wisdom, experience, and competence of community members (Stringer, 2013). By planning, acting, observing and reflecting, academic researchers in partnership with community members can uncover and consolidate existing knowledge and skills held within the community. Through collaborative work, participants can learn from each other, agree on possible actions, assess their impacts, then document lessons learned, creating a "spiral" of learning.

As a CBAR project, TEGS explored processes of social learning, and was not designed as intervention research using experimental or quasi-experimental designs. We therefore did not have control or comparison schools, nor were the same actions implemented at each school. 
Schools joined the project with varied food programs at different stages of development; teachers and administrators with a range of skills, interests and motivations; and diverse priorities, social, cultural, economic and physical contexts. Actions appropriate for, and of interest to, some schools were redundant to some or too advanced for others. University students served as key actors, participating in the delivery of school-based actions, gaining experiential learning opportunities, and valuable preparation for work as future engaged professionals. We believed that participation in collective learning, action, and knowledge production would unleash their creativity, passion, and capacity to imagine and work toward something better.

\section{Goals and objectives}

As illustrated by the logic model in Figure 1, TEGS worked on a spectrum of objectives ranging from achievable short-term outcomes to aspirational long-term goals. At the micro-level, objectives included: engaging K-12 students in and supporting teachers (and staff and volunteers) to provide hands-on whole food cycle education that included concrete opportunities for growing, preparing, and sharing food at school and sustainably managing food waste. We also engaged university students through undergraduate course curricula, as well as opportunities to conduct data collection and analysis, and to lead hands-on food literacy projects in classrooms.

At the meso-level (intermediate term) we aimed to empower future professionals, teachers, and policy makers to promote development of healthy, sustainable school food systems by nurturing connections between local actors, supporting policy development, and fueling existing local food movements to tackle complex problems in an ongoing way. At the macro-level (long term), TEGS aspired to contribute to enhanced regional food security, food system sustainability, and population health—but recognized that these goals would require action far beyond our timeline.

\section{Action projects and areas of impact}

Project efforts focussed on two interrelated categories of activities: action projects, and monitoring, and evaluation. As described below, action projects ranged from sharing financial resources with project partners through small grants, building capacity through professional development, catalyzing food system engagement through university student-led projects and workshops, and engaging in policy development initiatives.

\section{Small grants}

For each of the last four years of the project, research funding ( $\$ 20-\$ 35 \mathrm{~K} /$ year) was allocated to support school-based healthy and sustainable food system projects. School-based teams applied 
for funding annually (up to $\$ 2000$ per school); consequently, recipient schools became part of the Think\&EatGreen@School network and were expected to attend networking events, host UBC student-led classroom workshops, send representatives to professional development events, and share their experiences, progress, and learnings.

As illustrated in Figure 2, the Think\&EatGreen@School program rapidly grew from 15 schools in 2011-12 to 38 schools in 2014-15, representing schools from all six geographic sectors of VSB (Vancouver School Board, 2012). Over four years, \$110,000 was provided to 57 public schools, just over half of all public schools in Vancouver, fostering a network of connections within and between schools. At the end of each year, participating schools came together to share their learnings and progress. Each school created a poster report of results shared on the project website and posted at each school, and insights were further disseminated though a project newsletter and through the Vancouver School Network, an online platform created for collaboration (Mansfield, 2016).

The Small Grants initiative became a strategy for developing a strong community bound by relationships of reciprocity and trust. It also fostered integration of school-based teams into the larger project network, ensuring that individual school communities were supported to take concrete actions. School-based teams typically used funding to purchase: tools, cooking supplies, materials for building garden boxes and composting facilities, and release time for teachers to meet and plan activities and curricula related to TEGS' goals. Once they established gardens or cooking programs, many Small Grant schools then invited community-based non-profit organizations that had relevant expertise to help teachers develop hands-on-learning opportunities in new outdoor learning spaces and to acquire specific skills, such as how to use produce from the school's food garden in the classroom, how to recycle food waste into compost and return nutrients back to the soil. Beginningand end-of-year events attended by community partners and school teams, as well as team members' attendance at professional development events, facilitated a strong network of teachers engaged in hands-on food cycle education.

\section{Professional development}

Professional Development (Pro-D) activities included teacher workshops, annual Summer Institutes, and Teacher Education Practicums. Teacher workshops were delivered on province- and districtwide professional development days and through weekend mini-institutes and after-school sessions. Three-day Summer Institutes were offered at the beginning of July in 2011, 2012, and 2013 and over two Saturdays in the winter of 2014/15 school year (owing to job action in spring and summer 2014). The Institutes drew more than 90 participants each year. The workshops and institutes offered networking opportunities for teachers and community organizations and provided a variety of hands on classes focusing on: food gardens and orchards; composting and waste management; food procurement; food preparation and consumption; innovations in teaching and learning; and examination and discussions about school food policies. 


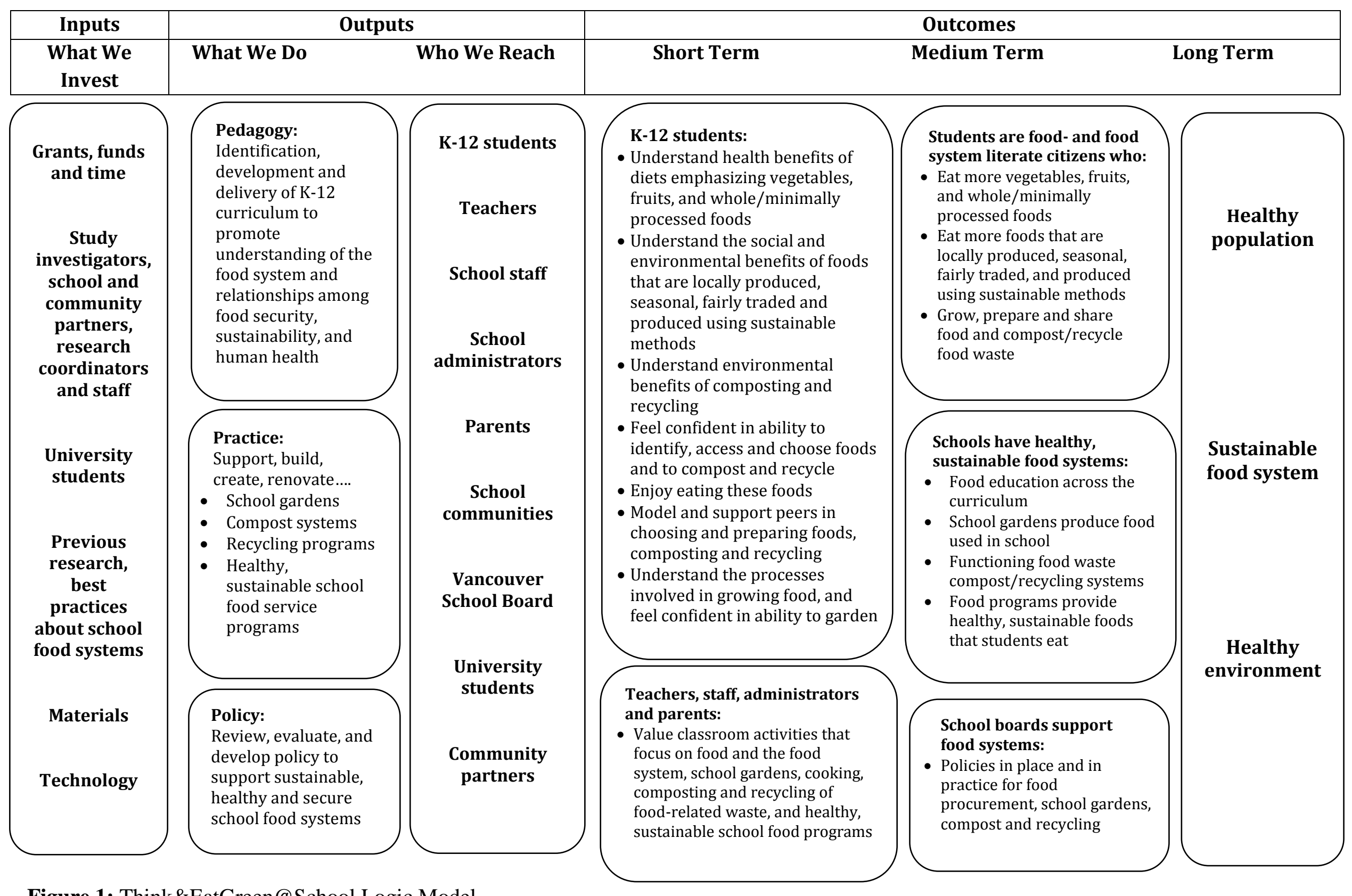

Figure 1: Think\&EatGreen@School Logic Model 
Figure 2: Geographic Distribution of Schools Receiving TEGS Small Grants in 2011-2015

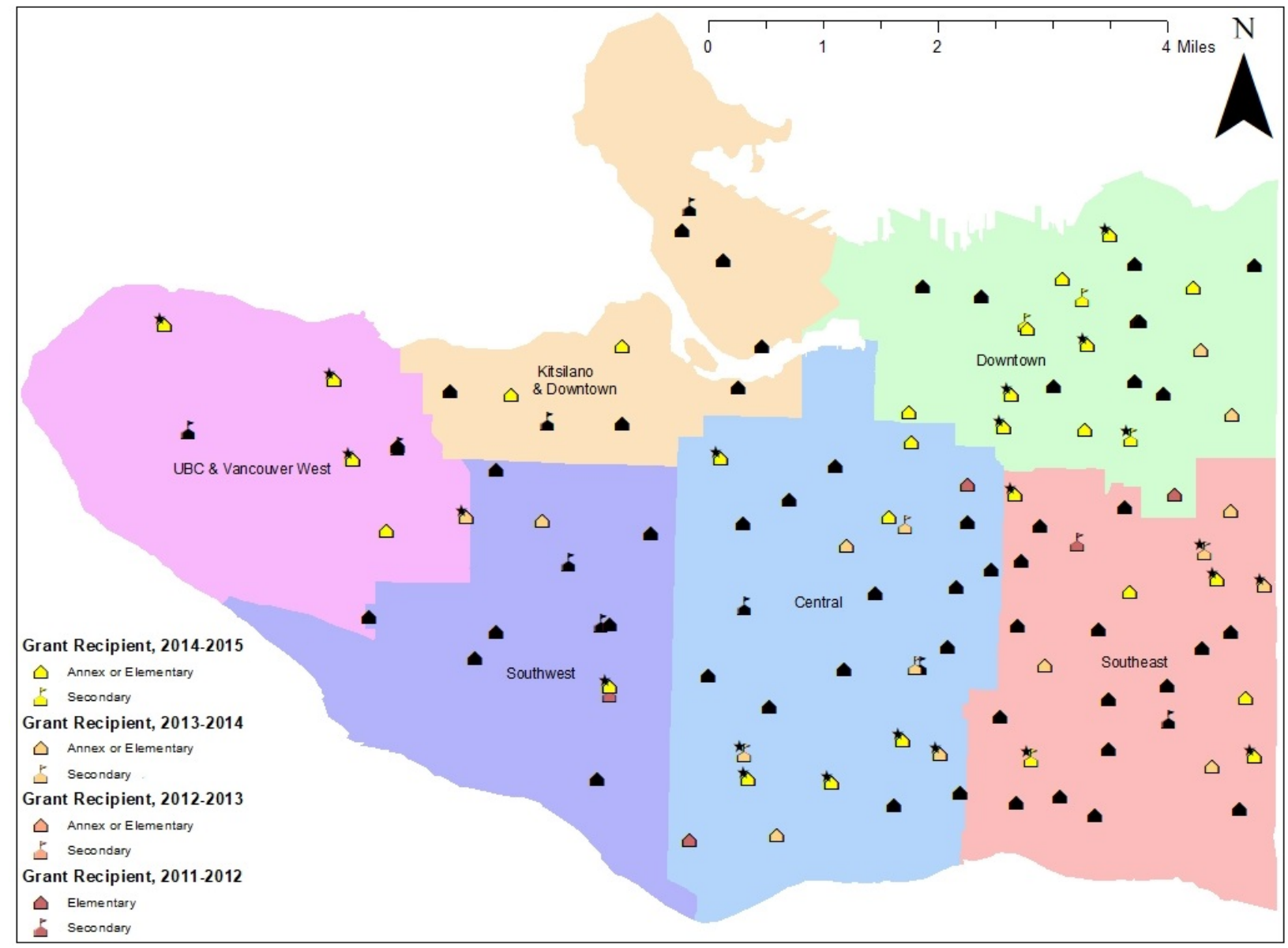

Grant recipient status is shown for the most recent year a school received a small grant. Stars indicate that the school received grants on more than one occasion. Schools symbolized in black received no small grants.

Teachers often attended multiple Pro-D events, including repeat attendance at Summer Institutes. Over time, many noted increased confidence in their ability to improve their school's food system and to enhance food cycle-education. In 2014, 45 teacher candidates from UBC's Bachelor of Education program completed a Community-Based Field Experience with a TEGS school or community partner where they participated in whole-food cycle hands on learning and explored "places of learning” outside of schools.

\section{Collaborative inquiry}

Two elementary schools participated in intensive collaboration where teacher teams met with researchers regularly (at least monthly) to explore together best approaches for increasing food and sustainability literacy among school teachers and students. Examples of initiatives undertaken in these schools included integrating produce from the school garden into a lunch 
salad bar and into curricular activities, establishing a school-wide compost system, and putting on a school-wide Earth Day event. For the latter event, very young elementary school children led poster presentations demonstrating their growing understandings of the links between environmental problems, food, and health.

\section{Community-Based Experiential Learning (CBEL)}

Each year, over 300 UBC students, through one of their university courses, were connected with an elementary or secondary school to conduct activities supporting food system education and to apply their classroom learning about food and environmental issues, nutrition, and health. Interdisciplinary teams of students participated in projects ranging from planning and building food gardens, planting garlic, creating classroom vermicomposting systems, to preparing and sharing healthy food with K-12 students. Over the duration of the project, approximately 2,000 undergraduate students engaged with 225 VSB classrooms and student clubs. Teachers' evaluation of university students’ performances indicated a high level of satisfaction with students' levels of professionalism and ability to relate sustainability and health-oriented content in an engaging manner. Undergraduate student feedback obtained through reflective course assignments revealed that participating in VSB activities positively impacted their own food literacy skills, their understanding of the complexity of school food systems, and the opportunities and challenges associated with efforts to address systemic food-related issues in society.

\section{Policy development and support}

Throughout the project, the TEGS network of actors was engaged in multiple policy initiatives. Contributions included key input on several school board, municipal and provincial policy initiatives including a food action plan for the Vancouver school board which informed VSB's sustainability framework (Millsip, 2010). The emerging interest and expertise in school gardens also impacted school garden policies and resources to support garden development (Vancouver School Board, 2010), and led to collaboration with community partners like Fresh Roots (Fresh Roots Urban Farm, 2012) to examine the feasibility of establishing market gardens on school grounds and how these gardens could be used in the cafeterias and curricula. TEGS actors also helped secure funding to examine sustainable food procurement practices through Farm to School Greater Vancouver and the Public Health Association of BC (PHABC). This led to the development of the School Food Procurement Learning Lab to explore opportunities to increase local, sustainable, and healthy procurement in Vancouver, and to identify necessary policy and regulatory changes required to facilitate change (Mansfield, 2016). Members also contributed to a Farm to School BC Provincial Task Force aiming to develop strategies for promoting and sustaining farm to school activities across the province (Mansfield, 2016). 


\section{Monitoring and evaluation activities}

Think\&EatGreen@School's monitoring and evaluation activities involved collecting a variety of qualitative and quantitative data to document project activities, outcomes of interest, and barriers and facilitators of change. We did not expect to observe large measurable changes in behavioural outcomes such as large dietary changes or substantial systems changes that could be directly attributed to specific project activities given the short project timeframe, diffuse nature of project activities, and recognition that food systems are complex and do not change rapidly. We did however, aspire to build capacity and engagement with food system issues and develop tools for measuring where schools were at.

\section{Key players study}

Qualitative interviews were conducted with 22 people identified as leaders in the development of programs and practices pursuing sustainable and healthy food systems in Vancouver public schools (Rojas, Orrego, \& Shulhan, 2015). This study identified motivations and challenges to key players' work, and innovative strategies they developed and adopted to support integration of food, sustainability, and health into the curriculum and school environments. Participants described the value of the practical skills, confidence, and attitudinal changes engendered through food-related initiatives, including the effectiveness of experiential, holistic, and other creative pedagogical strategies. They described food education as a "connector" of lessons and learners, and emphasized the importance of school-wide teamwork and collaborations among diverse stakeholders in food systems movements. This analysis reaffirmed the strengths of developing a community of co-learners, and using a Community-Engaged Scholarship framework. It highlighted how collaborations across networks and organizations, including the perceived legitimacy brought by having a university partner, strengthened both the actions and the research of this project.

\section{School Food Environment Assessment Tools (SFEAT)}

At the onset of the project, we recognized the need for more detailed understanding of what was happening within and across schools. How much did schools vary in level of engagement with food systems issues? What actions and food-related activities were already happening, and where were efforts most needed? Recognizing the absence of data speaking to these questions, we developed the SFEAT (School Food Environment Assessment Tools), a data collection and analysis framework designed using interviews with school administrators and food service staff, and direct observation of schools. The tools addressed six key domains: 1) food gardens; 2) composting systems; 3) food preparation activities; 4) food-related teaching and learning activities; and availability of 5) healthy food; and 6) environmentally sustainable food (Black et al., 2015). 
Between 2011-2013, SFEAT tools were applied in 33 diverse schools, showing that the development and use of food gardens and compost systems were the most highly developed domains across the sampled schools. Regular integration of food-related teaching and learning activities and hands-on food preparation experiences were also commonly reported. While most schools demonstrated some efforts to make healthy and environmentally sustainable food choices available, more work was needed to fully integrate programmes and policies that support healthy, environmentally sustainable food systems. Moreover, no schools reported widespread initiatives fully supporting availability or integration of healthy or environmentally sustainable foods across campus. We are continuing to refine and adapt these tools for widespread and ongoing use across the city for future monitoring and evaluation of food system change.

We also developed a shorter school self-assessment tool used annually by school-based teams receiving small grants to assess their progress. Self-assessments allowed schools to reflect on which domains they wanted to move forward on the following year and which supports were helping them progress. Small grant schools reported progress on domains of interest, often as a result of project participation, and described synergies with other local efforts and emerging policies to shape school food systems. Figure 3 provides a snapshot of types of data reported on the self-assessments and highlights the growth in number of TEGS small grant recipients in the latter years of the project. Overall, the majority of schools reported making progress across some domains measured each year and also expressed interest in continued growth. Garden engagement seemed to be an accessible entry point for many schools to start hands-on work with food systems, with over $75 \%$ of participating schools reporting making garden-related progress each year. Moreover, most schools reported some level of engagement with making healthy foods available. Yet, for the majority of schools, they were uncertain or reported no progress in making sustainable food available annually despite the majority reporting interest in doing so.

\section{Individual Eating Assessment Tool (IEAT)}

The IEAT was a self-reported survey developed to measure indicators at the student level, including: where, when and how often students procure and consume food on school days; the frequency of consuming fruits and vegetables, sugar-sweetened beverages, processed snacks, low-fat milk and whole grain foods; students' knowledge, self-efficacy, and attitudes related to healthy eating and food preparation; how the transition from elementary school to secondary school shapes students' social norms and food practices; and whether food system engagement is associated with students' knowledge, attitudes, or practices related to food. In 2012, the survey was administered to 950 students in grades 5-8 in 20 elementary and six secondary schools. Key findings are reported in three student theses and several peer reviewed papers (Ahmadi, 2013; Ahmadi, Black, Velazquez, Chapman, \& Veenstra, 2015; Daepp, 2016; Stephens, 2014; ; Stephens, Black, Chapman, Velazquez, \& Rojas, 2016; Velazquez, Black, Billette, Ahmadi, \& Chapman, 2015). 
Figure 3: Examples of Findings from TEGS Self-Assessment Surveys

\section{School Gardens}

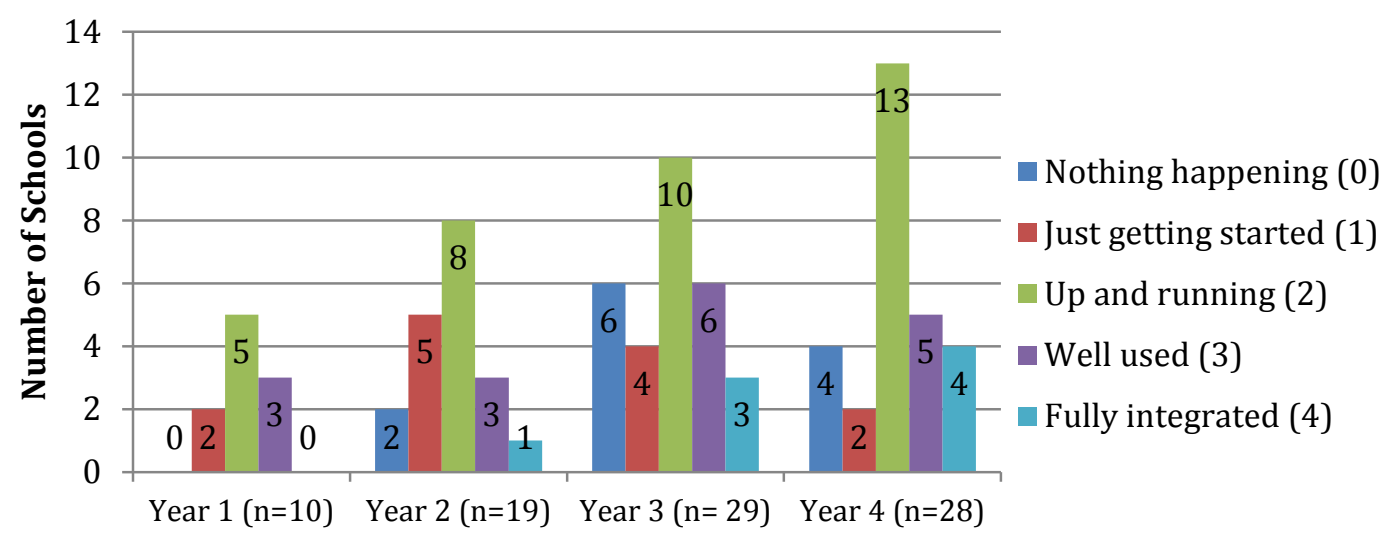

Healthy Food Availability

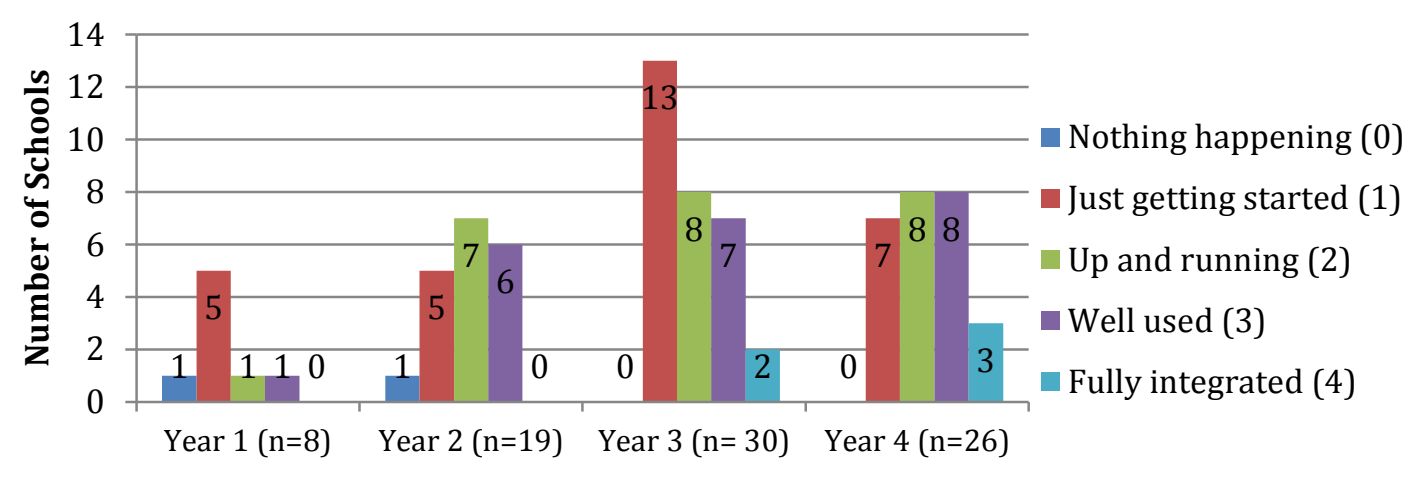

\section{Sustainable Food Availability}

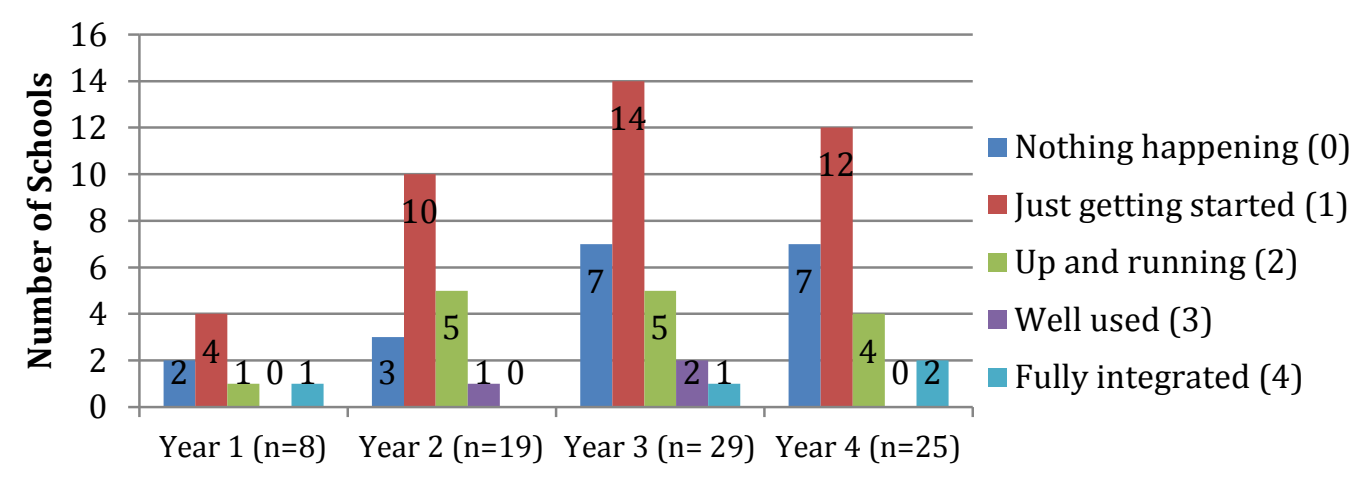




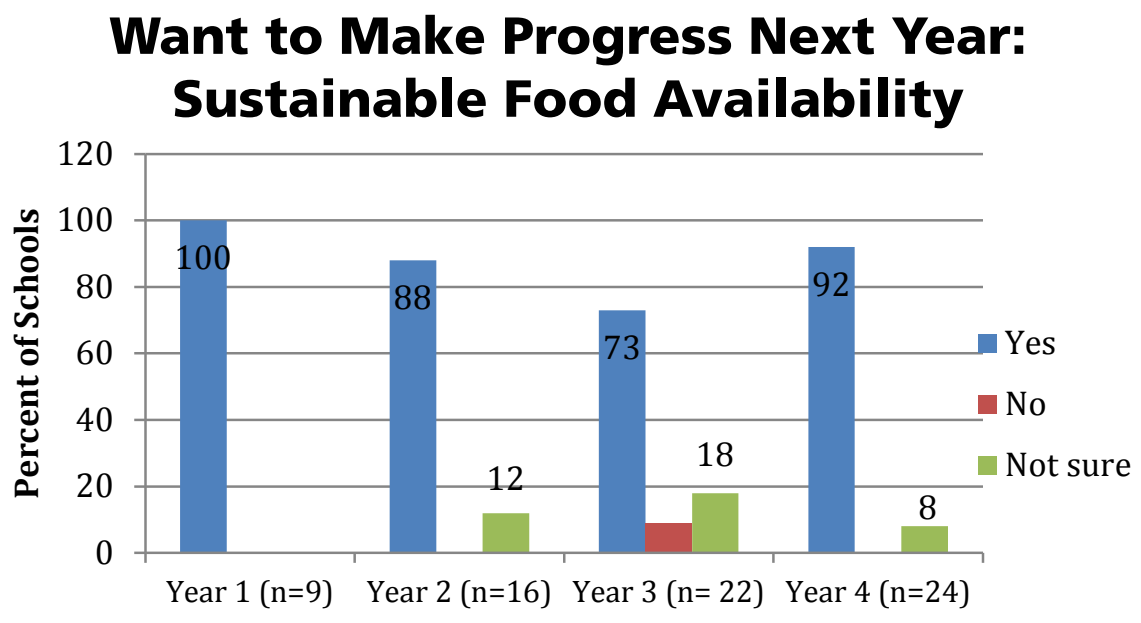

\section{Made Progress this Year: Sustainable Food Availability}

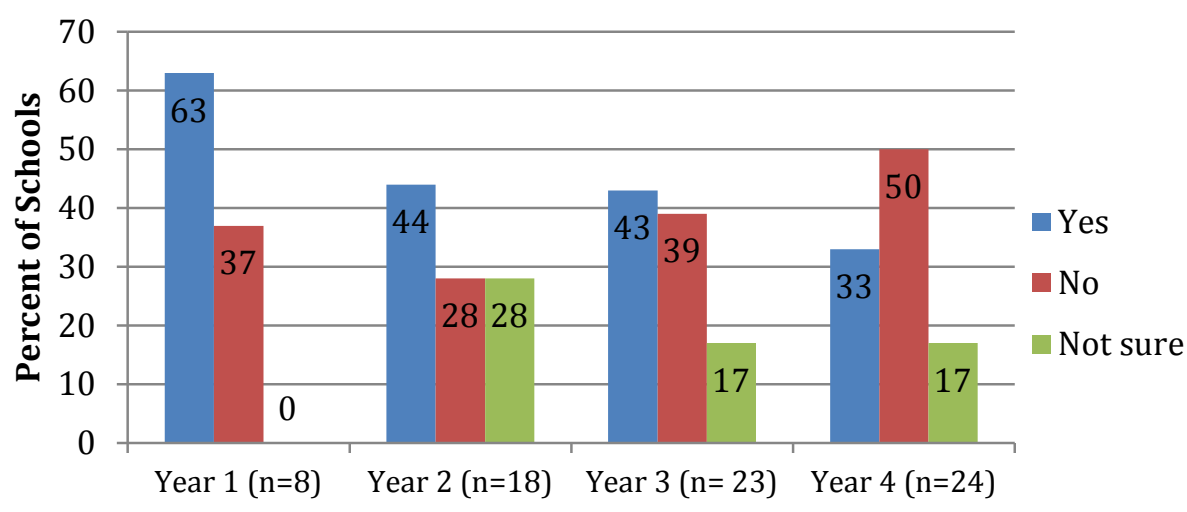

Note: Year 1=2011/12, Year 2=2012/2013, Year 3=2013/14, Year 4=2014/2015 Numbers per year differ across graphs owing to missing data.

Overall, IEAT findings suggested that in the 2011-2012 school year (reflecting the early years of TEGS), less than half of students reported engaging in most of the food and nutrition activities examined, including: food preparation (36\%), choosing/tasting healthy foods (27\%), learning about Canada’s Food Guide (CFG) (45\%), learning about foods grown in BC (35\%), gardening (21\%), composting (32\%), and recycling (51\%). Secondary students were more likely to report activities focused on working with or learning about food/nutrition, but overall participation in most activities was relatively low, with few students exposed to multiple food system activities. We were not able to conduct follow-up surveys, so can only speculate about whether food system engagement substantially increased either through direct exposure to TEGS activities or through capacity building, policy changes or shifting priorities among school staff or 
community partners. Still, the development of the IEAT tool and proposed strategies for measuring school food and nutrition activity engagement offered important baseline insight for comparison in future years.

Focus on Food was a qualitative study that sought to understand food culture among grade 9 and 10 students in Vancouver, and how they frame food choices. In semi-structured focus groups, student participants discussed their lunch selections and typical eating behaviours, perceived influences on those behaviours, and experiences and opinions about ways of eating that resonated with them (Shulhan, 2014). Findings suggested that students often framed food as either "good" (harmless) or "bad" (harmful), and tended to value natural foods and ingredients, while foods that seemed artificial or unfamiliar where treated with suspicion. Participants talked about trying to avoid or resist "bad" foods and to seek out "good" ones, and many wanted more information about or control over the foods made available to them. Students usually evaluated food in relation to human health concerns. Many also incorporated some ethical concerns, particularly those involving animal welfare, but for the most part, they were unfamiliar with links between food and environmental sustainability. Overall, Focus on Food findings suggested that future strategies to promote healthy and sustainable eating should continue to engage students in hands-on food-system related activities.

\section{Key learnings}

In this section we reflect on key learnings from TEGS to inform future projects aiming to tackle complex global food systems issues through actions in local contexts. First, our experiences reinforced the value of using a systems perspective to overcome the fragmentation of knowledge that we believe has contributed to current food systems problems. Before starting the project we observed how food-related topics were addressed in disconnected fragments in schools (e.g. with aspects of nutrition highlighted through discussion of Canada's Food Guide, cooking lessons in home-economics classes, discussion of food production, or distribution problems in agriculture courses). Food education was seldom integrated or comprehensive. We aimed to foster opportunities for gaining understanding of where food was coming from, how it was produced, processed, transported, distributed, consumed, and disposed of, and on how each aspect of the food cycle affects and is affected by other components. This includes how the food system is embedded in, and interacts with, larger ecological, economic, social, and cultural systems.

The project serves as an example of what is possible to that end: foremost, that a diverse, interdisciplinary and inter-organizational group could come together (and find research funding and institutional support) for a project that valued voices and experiences of academics, community groups, and local stakeholders. We demonstrated the feasibility of engaging with public schools to address food security, health, and environmental sustainability by focusing on integrating hands-on food cycle education across the curriculum and working to transform school food systems. Sharing the project's resources including time, expertise and funding (through the 
small grant mechanism, the Summer and Winter Institutes, and professional development activities) led to a reciprocal process of generosity that developed into an engaged network of actors including teachers, community organizations, and students. By requiring grant recipient teams to attend networking and professional development events and by linking them with university students and community partners, team members gained skills and confidence and were part of a growing network of committed people from which several "key players" emerged and helped build momentum.

We found evidence for the value of experiential, hands-on learning opportunities. Traditional classroom learning was supplemented by experiences where students could re-connect with the sources of food in nature, experience the transformation of food ingredients into appealing dishes, and experience the sensations of touching, smelling and tasting food. Food education is particularly suited to experiential learning. Gardening, cooking, and composting are all activities that can appeal to students' interests, engage all of their senses, and provide opportunities for students to fully experience and reflect on the results of their labour.

While we lacked formal measures of food literacy, we certainly increased opportunities for hands-on food cycle education across the curriculum. We documented new opportunities to support and build pedagogical innovations related to healthy, sustainable practices through activities like school gardens and hands-on food preparation, composting, and professional development for teachers. Despite many small outputs and growing numbers of engaged schools and participants in this project over six years, large scale food systems changes were more subtle and will require ongoing inputs. Opportunities to engage with policy development at the school board level, and working with municipal and provincial bodies to advocate for long term changes remain key actions for long term change.

We also had some (but not universal) success in integrating the traditional and often siloed academic roles of research, teaching, and service. For several of the project's investigators, this included teaching university courses where undergraduate students (and graduate student teaching assistants) contributed to data collection or hands-on actions in schools, and hence themselves became part of both action and research. Yet, we also noted the challenges of fitting this model of inquiry within a traditional academic rewards system that did not always lend itself well to this model of work. Additionally, involving undergraduate students in a community setting presents its own set of challenges, such as making a clear distinction between engagement and volunteering, preparing students for the uncertainty of work within the community, developing methods of accountability when conducting learning activities off-campus, and ensuring reciprocal benefits with community partners.

Still, we found great value in this form of social learning experimentation using a community-based participatory research approach that valued the connections between action and research, with the intent of producing knowledge and creating positive change. In contrast to dominant research designs that emphasize control by measuring outcomes of interventions, our research approach was emergent and context-specific. Schools and teachers self-selected into interventions. They chose which activities they would get involved in, and what to do in their 
schools based on the interests, history and context of the school community. This took place in a real world context where there were other facilitators, barriers and incentives to work on these issues. Therefore, it is difficult to say with any precision what impact TEGS had in isolation, which is a challenge for the current academic model and publication system. Although there was ample energy, involvement, and qualitative indication of impact, these metrics are more difficult to quantify.

\section{Conclusions and visions for the legacy of Think\&EatGreen@School}

While the formal funding for TEGS ended in 2015, its legacy continues through its "community of learners”. Through engaging multiple levels of students, community partners, schools, and academics, we have catalysed change; some which is measurable and much that does not lend itself to easy empirical indicators. The work accomplished required substantial investments from institutional commitments, funding, time, personnel, and human energy. As the formal funding and commitments wrapped up, the bulk of personnel and inputs were unable to continue with equal force, and questions remain about the long-term feasibility of this work. Nevertheless, efforts towards the project's long terms goals continue through the Vancouver School Food Network (Mansfield, 2016), continued collaboration between the school board and university partners to enhance food literacy education and food systems monitoring, and integration of projects within the UBC curriculum. Key learnings highlight the need for continued efforts to integrate research, teaching, and action on global food security, environmental and public health challenges. In tandem, we have demonstrated the importance of building connections to create healthy, sustainable school food systems.

Acknowledgements: Our work would not have been possible without the contributions of countless contributors including students, parents, and staff from the Vancouver School Board, University of British Columbia, Vancouver Coastal Health and community partners across Greater Vancouver. Many contributors also provided ideas and feedback that shaped this manuscript especially Adrienne Levay, Sarah Carten, Brent Mansfield, Matthew Kemshaw, Chessa Adsit-Morris, Cayley Velasquez, Naseam Ahmadi, Teya Stephens, Stephanie Shulhan and Madeleine Daepp who created our project maps. Funding support was from a Community University Research Alliances grant from the Social Sciences and Humanities Research Council of Canada (from the Think\&EatGreen@School project) and a Canadian Institute of Health Research Operating Grant (FNH 119577). 


\section{References}

Ahmadi, N. (2013). Examining the associations between socioeconomic status and school-day dietary intake among Vancouver children and adolescents. University of British Columbia. Retrieved from https://open.library.ubc.ca/cIRcle/collections/ubctheses/24/items/1.0073864

Ahmadi, N., Black, J. L., Velazquez, C. E., Chapman, G. E., \& Veenstra, G. (2015). Associations between socio-economic status and school-day dietary intake in a sample of grade 5-8 students in Vancouver, Canada. Public Health Nutrition, 18(5), 764-773.

Birch, L. L. (1999). Development of food preferences. Annual Review of Nutrition, 19, 41-62.

Black, J. L., \& Billette, J. M. (2013). Do Canadians meet Canada's Food Guide's recommendations for fruits and vegetables? Applied Physiology Nutrition and Metabolism, 38(3), 234-242.

Black, J. L., Velazquez, C. E., Ahmadi, N., Chapman, G. E., Carten, S., Edward, J., . . Rojas, A. (2015). Sustainability and public health nutrition at school: assessing the integration of healthy and environmentally sustainable food initiatives in Vancouver schools. Public Health Nutrition, 18(13), 2379-2391.

Briefel, R. R., Crepinsek, M. K., Cabili, C., Wilson, A., \& Gleason, P. M. (2009). School food environments and practices affect dietary behaviors of US public school children. Journal of the American Dietetic Association, 109(2 Suppl), S91-107.

Briefel, R. R., Wilson, A., \& Gleason, P. M. (2009). Consumption of low-nutrient, energy-dense foods and beverages at school, home, and other locations among school lunch participants and nonparticipants. Journal of the American Dietetic Association, 109(2 Suppl), S79-90.

City of Vancouver (2012). Greenest City: 2020 Action Plan. Retrieved from: http://vancouver.ca/files/cov/Greenest-city-action-plan.pdf

Coleman-Jensen, A., Rabbitt, M., Gregory, C., \& Singh, A. (2016). Household Food Security in the United States in 2015. ERR-215, U.S. Department of Agriculture, Economic Research Service. Retrieved from https://www.ers.usda.gov/webdocs/publications/79761/err215.pdf?v=42636

Cullen, T., Hatch, J., Martin, W., Higgins, J. W., \& Sheppard, R. (2015). Food Literacy: Definition and Framework for Action. Canadian Journal of Dietetic Practice and Research, 76(3), 140-145.

Daepp, M. I. G. (2016). The food environment surrounding Vancouver schools: associations of access to food outlets and children's intake of minimally nutritious foods at or en-route to school. Retrieved from https://open.library.ubc.ca/collections/24/items/1.0308712 
Davis, J. N., Spaniol, M. R., \& Somerset, S. (2015). Sustenance and sustainability: maximizing the impact of school gardens on health outcomes. Public Health Nutrition, 18(13), 23582367.

Etzkowitz, H. (2008). The triple helix: university-industry-government innovation in action. New York: Routledge.

EYA (2017). Environmental Youth Alliance - About EYA http://eya.ca/about-eya/

FAO, IFAD, \& WFP (2015). The State of Food Insecurity in the World 2015. Meeting the 2015 International Hunger Targets: Taking Stock of Uneven Progress. Rome: FAO. Retrieved from: http://www.fao.org/3/a-i4646e.pdf

Feenstra, G. (2002). Creating space for sustainable food systems: Lessons from the field. Agriculture and Human Values, 19(2), 99-106.

Foley, J. (2014). A Five-Step Plan to Feed the World. National Geographic Magazine. Retrieved from http://www.nationalgeographic.com/foodfeatures/feeding-9-billion/

Fraser, E., Legwegoh, A., Krishna, K., CoDyre, M., Dias, G., Hazen, S., . . S Sethuratnam, S. (2016). Biotechnology or organic? Extensive or intensive? Global or local? A critical review of potential pathways to resolve the global food crisis. Trends in Food Science \& Technology, 48, 78-87.

Fraser, E., \& Rimas, A. (2012). How to Feed Nine Billion. The Walrus. Retrieved from: http://thewalrus.ca/how-to-feed-nine-billion/

Fresh Roots Urban Farm (2012). About Us. Retrieved from: http://freshroots.ca/

Garriguet, D. (2007). Canadians' eating habits. Health Reports, 18(2), 17-32.

Godfray, H. C., Beddington, J. R., Crute, I. R., Haddad, L., Lawrence, D., Muir, J. F., . . . Toulmin, C. (2010). Food security: The challenge of feeding 9 billion people. Science, 327(5967), 812-818.

Government of Canada (2016). Health Canada's Healthy Eating Strategy. Retrieved from https://www.canada.ca/en/services/health/campaigns/vision-healthy-canada/healthyeating.html

Growing Chefs (2017). Our Mission. Retrieved from: http://www.growingchefs.ca/our-mission

Health Canada (2017). Children and Health Eating. Retrieved from: http://www.hc-sc.gc.ca/fnan/nutrition/child-enfant/index-eng.php 
Hersch, D., Perdue, L., Ambroz, T., \& Boucher, J. L. (2014). The impact of cooking classes on food-related preferences, attitudes, and behaviors of school-aged children: a systematic review of the evidence, 2003-2014. Preventing Chronic Disease, 11, E193.

IPCC (2014). Climate Change 2014: Synthesis Report. Contribution of Working Groups I, II and III to the Fifth Assessment Report of the Intergovernmental Panel on Climate Change [Core Writing Team, R.K. Pachauri and L.A. Meyer (eds.)]. IPCC, Geneva, Switzerland, 151 pp. Retrieved from http://epic.awi.de/37530/1/IPCC_AR5_SYR_Final.pdf

Kelder, S. H., Perry, C. L., Klepp, K. I., \& Lytle, L. L. (1994). Longitudinal tracking of adolescent smoking, physical activity, and food choice behaviors. American Journal of Public Health, 84(7), 1121-1126.

Legault, L., \& Pelletier, L. G. (2000). Impact of an environmental education program on students' and parents' attitudes, motivation, and behaviours. Canadian Journal of Behavioural Science, 32(4), 243-250.

MacPherson, M., de Groh, M., Loukine, L., Prud'homme, D., \& Dubois, L. (2016). Prevalence of metabolic syndrome and its risk factors in Canadian children and adolescents: Canadian Health Measures Survey Cycle 1 (2007-2009) and Cycle 2 (2009-2011). Health Promotion and Chronic Disease Prevention in Canada, 36(2), 32-40.

Mansfield, B. (2016). Growing the seeds of transition: The role of school food networks in scaling school food initiatives. University of British Columbia. Retrieved from https://open.library.ubc.ca/cIRcle/collections/ubctheses/24/items/1.0314122

Mayer-Smith, J., \& Peterat, L. (2010). Get Growing! Activities for food and garden learning. A teacher resource for elementary and middle grades. Vernon, BC: Really Small Vernon Press.

Mikkila, V., Rasanen, L., Raitakari, O. T., Pietinen, P., \& Viikari, J. (2005). Consistent dietary patterns identified from childhood to adulthood: the cardiovascular risk in Young Finns Study. British Journal of Nutrition, 93(6), 923-931.

Millsip, K. (2010). Sustainability Framework for the Vancouver School Board, Retrieved from http://www.vsb.bc.ca/sites/default/files/publications/SUSTAINABILITY\%20FRAMEWO $\underline{\mathrm{RK} \% 202 . p d f}$

Pelletier, C., Dai, S., Roberts, K. C., Bienek, A., Onysko, J., \& Pelletier, L. (2012). Report summary. Diabetes in Canada: Facts and figures from a public health perspective. Chronic Disease Injury in Canada, 33(1), 53-54.

Project Chef (2017). Project CHEF: Cook Healthy Edible Food. Retrieved from: http://www.projectchef.ca/ 
Roberts, K. C., Shields, M., de Groh, M., Aziz, A., \& Gilbert, J. A. (2012). Overweight and obesity in children and adolescents: results from the 2009 to 2011 Canadian Health Measures Survey. Health Reports, 23(3), 37-41.

Rojas, A., Orrego, E., \& Shulhan, S. (2015). Community-Based Action Research in Vancouver Public Schools: Improving the Quality of Children's Lives through Secure and Sustainable School Food Systems and Experiential Learning. Engaged Scholar Journal: CommunityEngaged Research, Teaching, and Learning, 1(2), 17-35.

Rojas, A., Valley, W., Mansfield, B., Orrego, E., Chapman, G. E., \& Harlap, Y. (2011). Toward Food System Sustainability through School Food System Change:

Think\&EatGreen@School and the Making of a Community-University Research Alliance. Sustainability, 3(5), 763-788.

Scaling Up Nutrition (2014). An Introduction to the Scaling Up Nutrition Movement. Retrieved from: http://ucx3x320eshgjxppibt1rag0.wpengine.netdna-cdn.com/wpcontent/uploads/2015/06/Orange_Internal_InOutline_ENG_20140415_web.pdf

Searchinger, T., Hanson, C., Ranganathan, J., Lipinski, B., Waite, R., Winterbottom, R., Dinshaw, A., and Heimlich R. (2013). Creating a Sustainable Food Future: Interim Findings. A Menu of Solutions to Sustainably Feed more than 9 Billion People by 2050. Washington: World Resources Institute. Retrieved From: http://www.wri.org/publication/creating-sustainable-food-future-interim-findings

Shulhan, S. (2014). Focus on Food: A Study of Food Culture among Vancouver Secondary School Students. University of British Columbia. Retrieved from https://open.library.ubc.ca/collections/24/items/1.0167435

SPEC (2017). Society Promoting Environmental Conservation-Practical Solutions for Sustainable Cities since 1969. Retrieved from: http://www.spec.bc.ca/

Stephens. (2014). Participation in School Food and Nutrition Programs and Associations with Dietary Psychosocial and Behavioural Outcomes among Vancouver Students in Grades 6-8. University of British Columbia, Vancouver. Retrieved from https://circle.ubc.ca/handle/2429/47090

Stephens, Black, J. L., Chapman, G. E., Velazquez, C. E., \& Rojas, A. (2016). Participation in School Food and Nutrition Activities among Grade 6-8 Students in Vancouver. Canadian Journal of Dietetic Practice and Research, 77(3), 148-153.

Stringer, E. T. (2013). Action Research. Los Angeles: Sage Publications.

Sumner, J. (2013). Food literacy and adult education: learning to read the world by eating. The Canadian Journal for the Study of Adult Education, 25(2), 79. 
Tarasuk, V., Mitchell, A., \& Dachner, N. (2016). Household Food Insecurity in Canada, 2014. Toronto: Research to Identify Policy Options to Reduce Food Insecurity (PROOF). Retrieved from http://proof.utoronto.ca/resources/proof-annual-reports/annual-report-2014/

Think\&EatGreen@School. (2015). Think \& Eat Green @ School Documentary (Longer Version "Embrace Change"). Vancouver, BC. Retrieved from https://thinkeatgreen.ca/ or https://video.search.yahoo.com/yhs/search?fr=yhs-adk-adk_sbnt\&hsimp=yhsadk_sbnt\&hspart=adk\&p=Think+and+Eat+Green+at+School+Youtube\#id=1\&vid=e872ce e57a4014cd1c357303fd47e00d\&action=click

Tremblay, M. S. (2012). Major initiatives related to childhood obesity and physical inactivity in Canada: the year in review. Canadian Journal of Public Health, 103(3), 164-169.

Trencher, G., Yarime, M., McCormick, K. B., Doll, C. N. H., \& Kraines, S. B. (2013). Beyond the third mission: Exploring the emerging university function of co-creation for sustainability. Science and Public Policy, 41(2), 151-179.

Tugault-Lafleur, C. N., Black, J. L., \& Barr, S. I. (2017). Examining school-day dietary intakes among Canadian children. Applied Physiology Nutrition and Metabolism, 1-9.

United States Department of Agriculture (2015). 2015 Dietary Guidelines: Giving You the Tools You Need to Make Healthy Choices. Access June 12, 2017 Retrieved from http://blogs.usda.gov/2015/10/06/2015-dietary-guidelines-giving-you-the-tools-you-needto-make-healthy-choices/

Vancouver School Board (2010). VBE School Food Garden Policy Statement. https://www.vsb.bc.ca/district-policy/io-garden-policy

Vancouver School Board (2012). Vancouver School Board Sectoral Review Our Schools, Our Programs, Our Future. Retrieved from: https://www.placespeak.com/uploads/assets/sectoral-review-mar30.pdf

Velardo, S. (2015). The Nuances of Health Literacy, Nutrition Literacy, and Food Literacy. Journal of Nutrition Education and Behavior, 47(4), 385-U122.

Velazquez, C. E., Black, J. L., Billette, J. M., Ahmadi, N., \& Chapman, G. E. (2015). A Comparison of Dietary Practices at or En Route to School between Elementary and Secondary School Students in Vancouver, Canada. Journal of the American Dietetic Association, 115(8), 1308-1317.

Welker, E., Lott, M., \& Story, M. (2016). The School Food Environment and Obesity Prevention: Progress Over the Last Decade. Current Obesity Reports, 5(2), 145-155.

Winson, A. (2010). The Demand for Healthy Eating: Supporting a Transformative Food “Movement”. Rural Sociology, 75(4), 584-600. 